\title{
Development of Capacitive Rain Gauge for Marine Environment
}

\author{
Hui Chai $\mathbb{D}$, Shixuan Liu $\mathbb{D}$, Xianglong Yang, Xiaozheng Wan, Shizhe Chen $\mathbb{D}$, Jiming Zhang, \\ Yushang Wu, Liang Zheng, and Qiang Zhao
}

Institute of Oceanographic Instrumentation, Qilu University of Technology (Shandong Academy of Sciences), Qingdao 266061, China

Correspondence should be addressed to Shizhe Chen; hcszom@163.com

Received 24 November 2020; Revised 19 February 2021; Accepted 12 March 2021; Published 7 April 2021

Academic Editor: Yuan Li

Copyright $\odot 2021$ Hui Chai et al. This is an open access article distributed under the Creative Commons Attribution License, which permits unrestricted use, distribution, and reproduction in any medium, provided the original work is properly cited.

\begin{abstract}
At present, the methods and instruments for measuring the precipitation on land may not effectively work in the offshore corrosion environment which is characterized by salt and humid. The research look at investigating the reliable and precision approach of measuring rainfall and a capacitive rain gauge for the marine environment is developed. Firstly, according to the working principle and performance requirements of the capacitive rain gauge, the modular mechanical structure and capacitance voltage conversion circuit of the rain gauge are designed, and the calibration and stability experiments of the prototype are tested to evaluate the measurement error and exam the accuracy of the rain gauge measurement results changing over time. Then, environmental adaptability experiment is carried out on the capacitive rain gauge to explore its performance in the environment of temperature and humidity changes as well as salt spray. Finally, the feasibility of the rain gauge used in the marine environment is verified by the sea test of the prototype. The measurement error of the developed capacitive rain gauge is less than $1 \mathrm{~mm}$, which provides a realization method for the measurement of precipitation in the marine environment.
\end{abstract}

\section{Introduction}

The measurement for oceanic precipitation is one of the basic elements of marine meteorological observation, which is significant to the study of marine weather and climate change, water, and energy cycle system as well as numerical weather forecast [1-3]. Rainfall measurement can be obtained directly by rain gauge $[4,5]$ and can also be indirectly estimated by weather radar [6] and retrieved by satellite remote sensing [7] and microwave link attenuation $[8,9]$. Compared with radar estimation, satellite remote sensing, and microwave link attenuation retrieval of rainfall, the accuracy of rainfall measured by rain gauge is the highest and is usually used as a comparison benchmark for evaluating other precipitation measurement methods [10-12]. However, the rain gauge is a single point precipitation measurement tool and unable to obtain the precipitation in a large area. To solve this problem, the rainfall station network is designed for measuring regional precipitation, and this network has been widely used on land $[13,14]$.
The main methods of measuring precipitation by rain gauge mainly include water-holding method [15], optical method [16], acoustic method [17], and piezoelectric effect method [18]. The water-holding method obtains rainfall by measuring the change of water weight or volume in the container, optical method adopts the principle of diffuse reflection caused by raindrop passing through laser or infrared light to predict rainfall, acoustic method uses acoustic reflection to measure precipitation, and the rain gauge applying piezoelectricity effect estimates raindrop spectrum and precipitation through perception raindrop momentum changing. Among these methods, the optical method, acoustic method, and piezoelectric effect method apply optics lens, acoustic probe, and piezoelectric patches as perception elements, respectively, and these sensing parts or elements are susceptible to the surrounding environment such as noise, dust, and corrosive; so, these methods are easy to cause measurement error and rarely used in rough environmental conditions $[19,20]$. The rain gauge adopting the water-holding method has few environment sensitive parts comparing with other types of rain gauge; so, it has advantages in high 


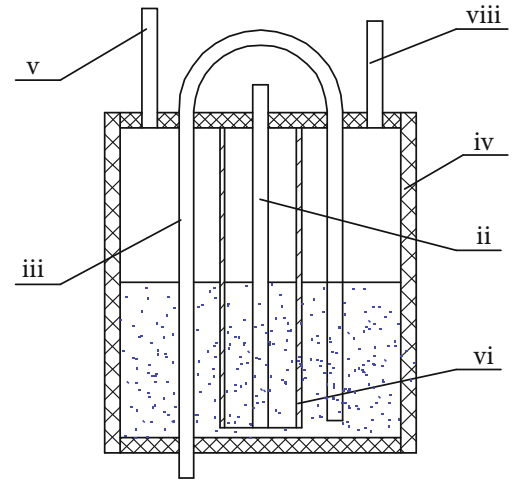

(a)

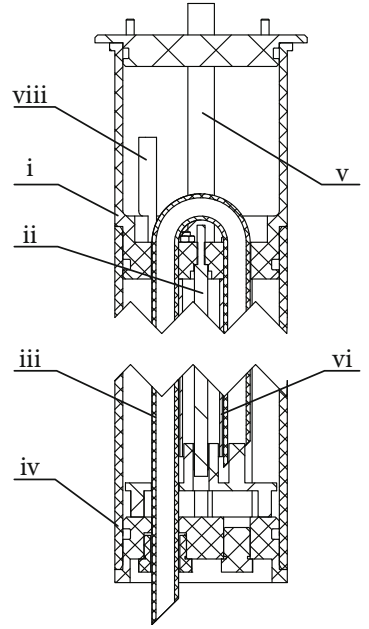

(b)

FIgURE 1: Schematic diagram (a) and structure diagram (b) of the capacitive rain gauge with (i) water inlet support, (ii) electrode rod, (iii) drainage pipe, (iv) water container, (v) water inlet pipe, (vi) electrode pipe, (vii) shell, and (viii) vent pipe.

accuracy and adaptability and is widely used for measuring rainfall.

There are mainly three kinds of rain gauges for measuring precipitation by the water-holding method: tipping bucket type [21], siphon type [22], and weighting type [23]. The performance of these rain gauges varies according to the measure principle, and there exists certain deficiencies among these rain gauges when they are used in different conditions. For example, the tipping bucket rain gauge is easy to be affected by rain intensity, and its measurement error increases with rain intensity increasing [24]. When the rain intensity is small, a measure error will happen for siphon rain gauge [25]. In the case of heavy rainfall, the weighting rain gauge is prone to miss precipitation data; so, the stability of measurement results is insufficient [26]. In addition, the tipping bucket rain gauge and siphon rain gauge have mechanical transmission parts, which are difficult to work stably and reliably in the marine environment with the characteristic of humidity and salt spray, and for this reason, the rain gauges need to be regularly maintained. However, the maintenance for the rain gauge used in severe or unattended environment is difficult. Hence, the measure accuracy and operation reliability in various environment are needed to give serious consideration when a rainfall measuring apparatus is developed.

It has been utilized in rain gauge to compose network on land to measure rainfall in large area; however, the rainfall monitoring about a large area at sea using rain gauge is not implemented. So far, the use of rain gauge to measure precipitation at sea mainly relies on ship $[19,27]$ and ocean buoy $[28,29]$. However, the ship route selection, ship movement, and ship superstructure all affect the rainfall measurement area and results $[19,27]$. The density of the buoy in the sea is still low, and the spatial distribution is uneven, which cannot meet the needs of large-scale regional rainfall monitoring. With the exploitation of marine resources and development of ocean observation technology, more and more drilling platforms, wind and ocean energy power gen- eration devices, and ocean observation equipment will be deployed near-globe seas, and these ocean platforms will become the ideal platform to carry rain gauge; so, it can be predicted that an increasing number of rain gauge will be installed on ocean platforms to carry out large-scale marine precipitation measurement in the future. Although some technologies based on the methods mentioned above for measuring rainfall at sea have been carried out, and the measurement accuracy is similar to that of used on land, the weatherability, environment adaptability, and data integrity still need to be further verified or perfected $[18,19]$. Therefore, it is necessary to pay close attention to study the feasibility method for measuring precipitation and elaborate a rain gauge that works precisely and reliably in the marine corrosive environment for a long-term application.

From the point of technical feasibility and working reliability, a type of capacitive rain gauge that is able to adapt to the marine environment was developed in this paper. The modular mechanical structure, circuit design, laboratory performance trial, and offshore test of the rain gauge were systematically studied, which provided an effective and feasible technical method and selection scheme for obtaining the marine precipitation.

\section{Materials and Methods}

This part first introduces the working principle of the capacitive rain gauge, then describes the hardware composition of the developed capacitive rain gauge, and finally shows the performance test method of the rain gauge.

2.1. Working Principle. The rainfall measure method of the gauge presented in this paper is based on the principle of capacitive sensor for liquid level measurement [30]. The schematic diagram of the capacitive rain gauge is shown in Figure 1(a). The electrode rod, electrode tube, and the air and the water between the electrode rod and electrode tube constitute a cylindrical capacitor, and the axe of the water 


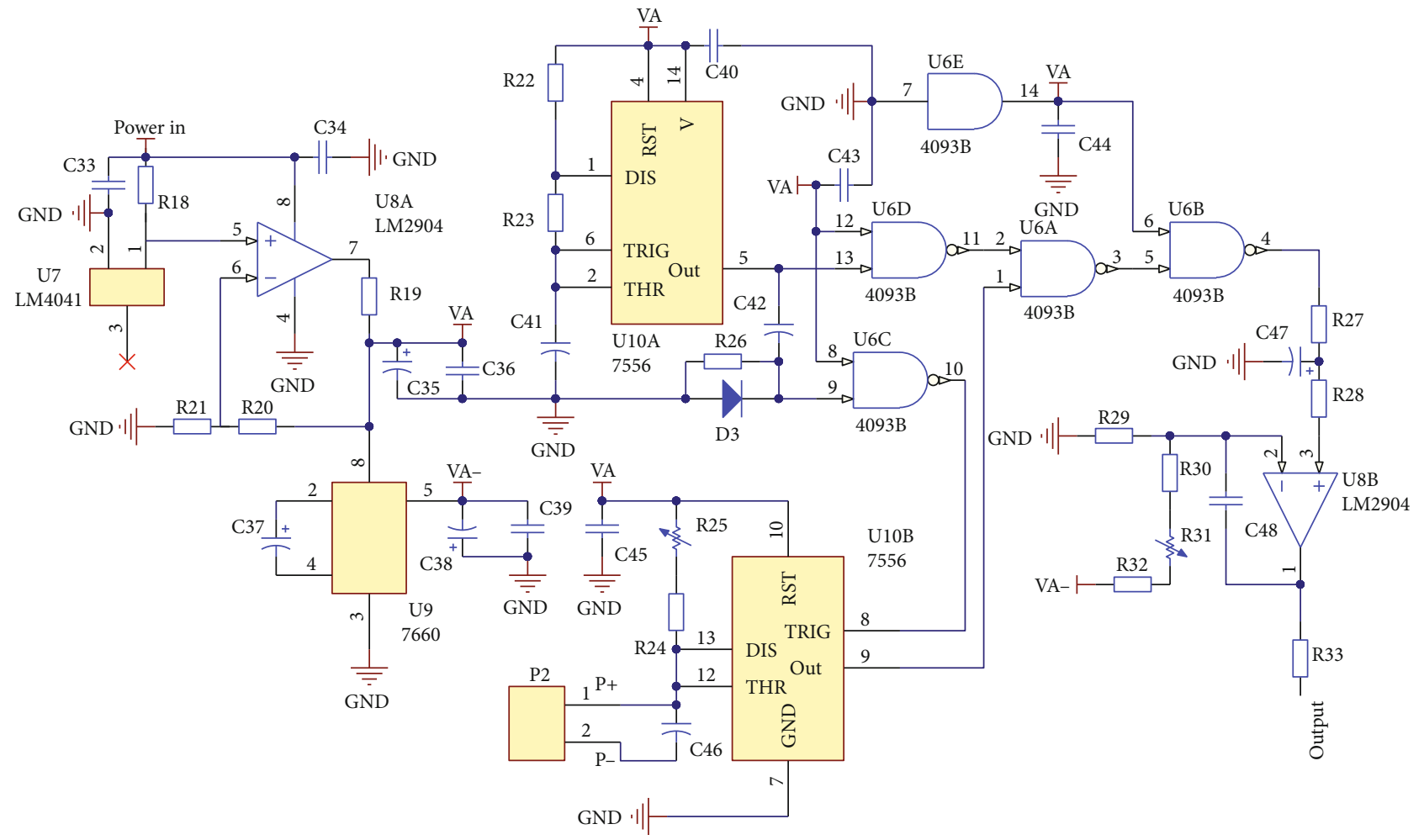

Figure 2: Circuit design of the capacitive rain gauge.

container, electrode tube, and electrode rod is colinear. When rain falls, the precipitation enters into the water container through the water inlet pipe and as a result, the water level in the electrode tube will change, which will cause the change of capacitance value. The precipitation can be measured by measuring the changed capacitance value.

The whole cylinder capacitor can be regarded as the capacitor $c_{1}(\mathrm{~F})$ with water as its dielectric and the capacitor $c_{2}(\mathrm{~F})$ with air as its dielectric in parallel. The inner circle radius of the electrode tube is $r_{1}(\mathrm{~mm})$, the radius of the electrode rod is $r_{0}(\mathrm{~mm})$, the height of water container is $L(\mathrm{~mm})$, and the height of the internal water level is $l(\mathrm{~mm})$. The dielectric constants of vacuum, water, and air are $\varepsilon_{0}, \varepsilon_{1}$, and $\varepsilon_{2}$, respectively. The theoretical values of $c_{1}$ and $c_{2}$ are

$$
c_{1}=\frac{2 \pi \varepsilon_{0} \varepsilon_{1} l}{\ln \left(r_{1} / r_{0}\right)}, c_{2}=\frac{2 \pi \varepsilon_{0} \varepsilon_{2}(L-l)}{\ln \left(r_{1} / r_{0}\right)} .
$$

The capacitance $c(F)$ of the whole cylinder capacitor can be expressed as

$$
c=c_{1}+c_{2}=\frac{2 \pi \varepsilon_{0} \varepsilon_{2} L}{\ln \left(r_{1} / r_{0}\right)}+\frac{2 \pi \varepsilon_{0}\left(\varepsilon_{1}-\varepsilon_{2}\right)}{\ln \left(r_{1} / r_{0}\right)} l .
$$

According to Equation (2), the capacitance $c$ is a linear function of the water level height $l$, and there is a one-toone match between the capacitance value and water level height. When the water level rises to the top of U-shaped drainage pipe, the precipitation value is the maximum, and the siphon phenomenon will occur at this time. As a result, the precipitation in the water container is discharged by the drainage pipe, the measured value of rainfall returns to zero, and the measurement of precipitation starts again for next cycle.

\subsection{Hardware System Design}

2.2.1. Mechanical Structure Design. The capacitive rain gauge is composed of mechanical part and circuit part. As shown in Figure 1(b), the modular mechanical part is mainly composed of outside shell and internal structure. The internal structure is the core part of the rain gauge and mainly includes water inlet support, water container, drainage pipe, electrode rod, electrode tube, and circuit. The shell, on one hand, is used to protect and seal the internal parts, and on the other hand, it is used to accommodate precipitation and to provide a mounting location with offshore platform. The circuit elements are installed in the water inlet support of the internal structure.

The maximum volume of the water container $V(\mathrm{ml})$, the maximum precipitation $H(\mathrm{~mm})$ in one measuring cycle, and the effective cross-sectional area $S\left(\mathrm{~mm}^{2}\right)$ of the water container are all set values according to the designed requirements. The diameter of shell upper end $D(\mathrm{~mm})$ and the height of water container $L(\mathrm{~mm})$ can be expressed as follows:

$$
D=\frac{2}{\sqrt{\pi}} \sqrt{\frac{V}{H}}, L=\frac{\mathrm{V}}{S}=\frac{\pi D^{2}}{4 S} H .
$$

Equation (3) can also be used to characterize the relationship between the water level changing $\Delta l(\mathrm{~mm})$ and 
precipitation $h(\mathrm{~mm})$ over a period of time:

$$
\Delta l=\frac{\pi D^{2}}{4 S} h .
$$

Compared with the existing tipping bucket rain gauge and siphon rain gauge, the proposed capacitive rain gauge has no mechanical transmission parts, which can effectively improve the reliability of the system in the oceanic environment. In addition, all parts of the rain gauge are made of ant-corrosion and weather resistance materials considering the corrosive environment of high salt and humidity on the sea: except for the electrode rod, electrode tube, and fastening connector which are made of stainless steel, and the other parts are made of polycarbonate or polymethyl methacrylate. The circuit components and wiring points are treated with moisture proof, salt fog proof, and mould proof technology.

2.2.2. Circuit Design. In order to achieve high-precision measurement, the circuit of the rain gauge is meticulously designed. The circuit diagram of the system is shown in Figure 2. Because there is a one-to-one correspondence between capacitance and precipitation, the capacitance is output in the form of voltage. It is the key of circuit design to accurately measure the capacitance value of the capacitor composed of electrode tube, electrode rod, and dielectric between them and convert the capacitance value into the voltage value. The circuit system is mainly composed of reference oscillation circuit, oscillation modulation circuit, phase discrimination shaping circuit, and integral amplifier circuit. The reference oscillation circuit and the oscillation modulation circuit preprocess the input capacitance data and modulate pulse width, respectively, and then generate rectangular pulse through the phase discrimination and shaping circuit. Finally, the corresponding voltage signal is obtained through the integral amplifier circuit.

According to Equations (2) and (4), the relationship between capacitance change $\Delta c(\mathrm{~F})$ and precipitation $h$ $(\mathrm{mm})$ for a precipitation process can be obtained:

$$
\Delta c=\frac{2 \pi \varepsilon_{0} \varepsilon_{2} L}{\ln \left(r_{1} / r_{0}\right)}+\frac{\pi^{2} \varepsilon_{0}\left(\varepsilon_{1}-\varepsilon_{2}\right) D^{2}}{2 \ln \left(r_{1} / r_{0}\right) S} h .
$$

The relationship between output voltage $u(\mathrm{~V})$ and capacitance $c(\mathrm{~F})$ according to circuit analyses can be expressed as follows:

$$
u=\mathrm{A} c+\mathrm{B}
$$

where $A(\mathrm{~V} / \mathrm{F})$ and $B(\mathrm{~V})$ are constants related to circuit parameters.

According to Equations (5) and (6), the relationship between output voltage $u$ and capacitance $c$ is linear. The precipitation in a certain period can be obtained by calculating the change value of output voltage. The input voltage of the system is $12 \mathrm{~V}$, and the output voltage is $0-5 \mathrm{~V}$, corresponding to $0-50 \mathrm{ml}$ precipitation.

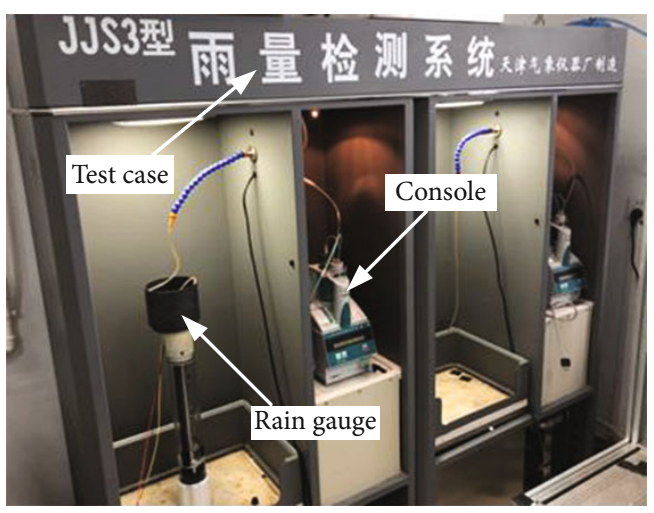

FIgURE 3: Calibration test and stability experiment of the rain gauge.

\subsection{Experiments}

2.3.1. Calibration Experiment. In order to determine the relationship between the precipitation and the output voltage value of the capacitive rain gauge and even evaluate the measurement error and test the accuracy of the measurement results, the developed rain gauge was calibrated. The calibration experiment of rain gauge is shown in Figure 3, and it can be seen that the rain gauge calibration system is composed of two parts: test case and console. The test case is used to place the rain gauge and add water to the rain gauge. The console is used to precisely control the amount of water added and process the output voltage value.

The calibration method is as follows: the test case injects ration water into the rain gauge from $0 \mathrm{ml}$ to the maximum value of $500 \mathrm{ml}$ by $50 \mathrm{ml}$ interval, which corresponds the precipitation increasing correspondingly from $0 \mathrm{~mm}$ to $50 \mathrm{~mm}$ by $5 \mathrm{~mm}$ interval, and the interval time of adjacent water injection is 3 minutes. At the same time, the output voltage is collected by data collector of console. Once the water capacity reaches $500 \mathrm{ml}$, siphon will occur, and the water injection and measurement process will be repeated after emptying. The process of water injection and measurement is carried out for three times, and for the same volume injection, the average value of the three output voltage values is taken as the measurement voltage.

2.3.2. Stability Experiment. In order to test the stability of measurement results of the developed capacitive rain gauge over time, the stability experiment was carried out using the same experiment system shown in Figure 3. The test method is as follows: the water in the rain gauge is drained and injects $50 \mathrm{ml}, 150 \mathrm{ml}, 250 \mathrm{ml}, 350 \mathrm{ml}$, and $450 \mathrm{ml}$ water orderly into the rain gauge every 5 days to simulate the precipitation of $0 \mathrm{~mm}, 5 \mathrm{~mm}, 15 \mathrm{~mm}, 25 \mathrm{~mm}, 35 \mathrm{~mm}$, and $45 \mathrm{~mm}$. For each water injection point, the output voltage is collected at a sampling interval of 10 minutes for 5 days, and the change of voltage data during the period is recorded.

2.3.3. Environmental Adaptability Experiment. The developed capacitive rain gauge is mainly used in the marine environment. In order to investigate the possible issues of the prototype and test the adaptability and reliability of the rain 


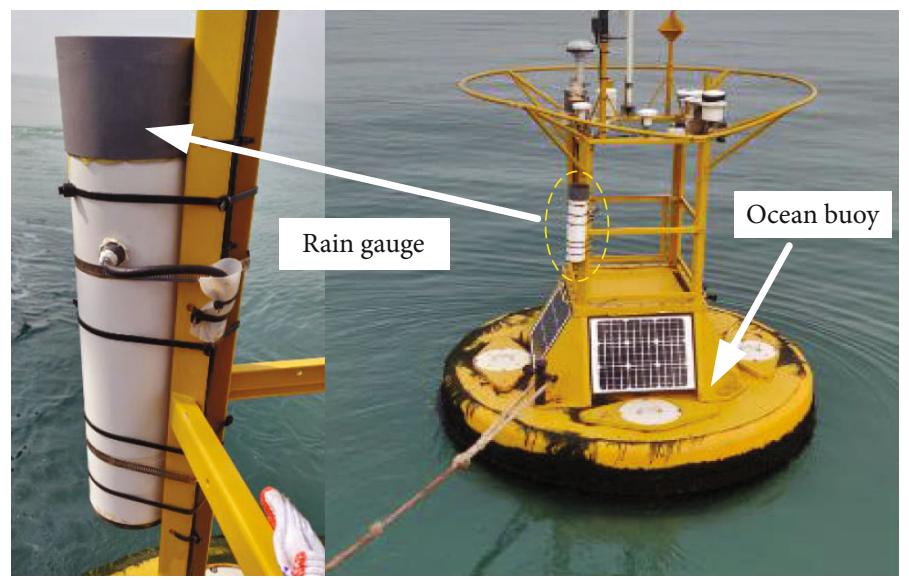

FIGURE 4: Offshore experiment of the rain gauge.

TABLe 1: Calibration data of rain gauge.

\begin{tabular}{lcccc}
\hline $\begin{array}{l}\text { Measuring } \\
\text { point [ml] }\end{array}$ & $\begin{array}{c}\text { Nominal } \\
\text { voltage } \\
{[\mathrm{V}]}\end{array}$ & $\begin{array}{c}\text { Measuring } \\
\text { voltage [V] }\end{array}$ & $\begin{array}{c}\text { Precipitation } \\
\text { error [mm] }\end{array}$ & $\begin{array}{c}\text { Uncertainty } \\
{[\mathrm{mm}]}\end{array}$ \\
\hline 0 & 0 & 0.008 & 0.08 & 0.001 \\
50 & 0.5 & 0.551 & 0.51 & 0.001 \\
100 & 1.0 & 1.071 & 0.71 & 0.001 \\
150 & 1.5 & 1.532 & 0.32 & 0.001 \\
200 & 2.0 & 2.010 & 0.10 & 0.002 \\
250 & 2.5 & 2.501 & 0.01 & 0.002 \\
300 & 3.0 & 2.980 & -0.20 & 0.002 \\
350 & 3.5 & 3.480 & -0.20 & 0.003 \\
400 & 4.0 & 4.001 & 0.01 & 0.003 \\
450 & 4.5 & 4.510 & 0.10 & 0.003 \\
500 & 5.0 & 4.990 & 0.10 & 0.003 \\
\hline
\end{tabular}

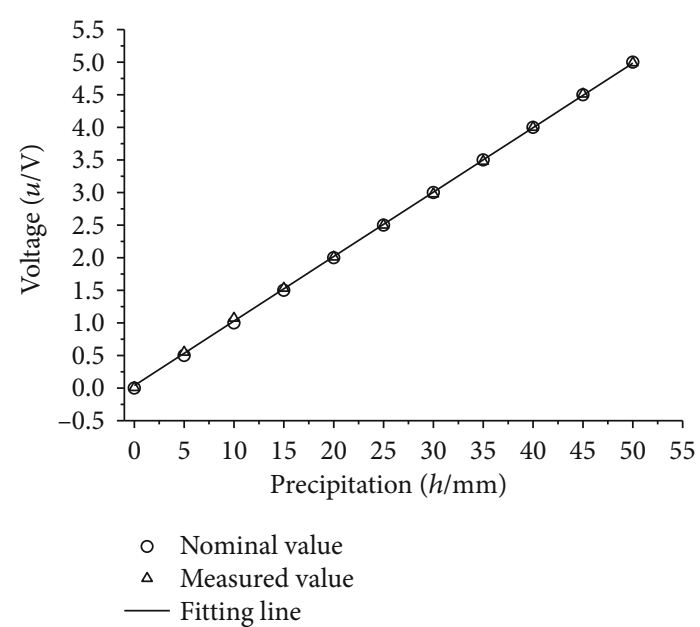

Figure 5: Calibration curve of output voltage with precipitation.

gauge in the marine environment, the environmental adaptability experiment of the rain gauge is carried out. Environmental adaptability experiment for oceanic rain gauge includes temperature test and salt spray test. During the tem- perature test, the working capacitive rain gauge is placed in a constant temperature and humidity box. The humidity is set to $95 \% \mathrm{RH}$, and the temperature varies from $-10^{\circ} \mathrm{C}$ to $50^{\circ} \mathrm{C}$ by $10^{\circ} \mathrm{C}$ interval. The temperature test for each temperature point lasts 72 hours. During the salt spray test, the cleaned capacitive rain gauge is put into the salt spray box, and 5\% sodium chloride solution ( $\mathrm{pH}$ value between 6.5 and 7.2) is atomized by ultrasonic cavitation to simulate the salt spray corrosion environment. The salt spray experiment lasts for 48 hours. After the test, the salt deposits on the surface of the shell are washed with flowing water, and the rain gauge is placed in the indoor environment for 1-2 hours to observe its appearance structure.

2.3.4. Offshore Experiment. In order to exam the performance of the developed capacitive rain gauge in the marine environment, the developed rain gauge is installed on the marine monitoring buoy which is 1.8 kilometers out of the land in Weihai on the coast of the Yellow Sea for offshore experiment as shown in Figure 4. The power supply of the rain gauge is provided by solar battery on the buoy, and the output voltage data is processed by the buoy control system and then transmitted back to land by the communication system in real time.

\section{Results and Discussion}

The designed capacitive rain gauge is mainly used in the marine environment, which requires high reliability and measurement accuracy. The specific performance requirements are as follows: precipitation measurement range is 0 $50 \mathrm{~mm}$, and measurement accuracy is $1 \mathrm{~mm}$.

According to the calibration method mentioned above, the calibration is carried out, and the calibration data are shown in Table 1. It can be seen from Table 1 that when the water volume increases from $0 \mathrm{ml}$ to $500 \mathrm{ml}$ by $50 \mathrm{ml}$ interval, the measurement error of each calibration point is within $\pm 1 \mathrm{~mm}$, and the maximum measurement error and maximum uncertainty are $0.71 \mathrm{~mm}$ and $0.003 \mathrm{~mm}$, respectively, which meet the designed requirements of the capacitive rain gauge. However, the calibration results about the 


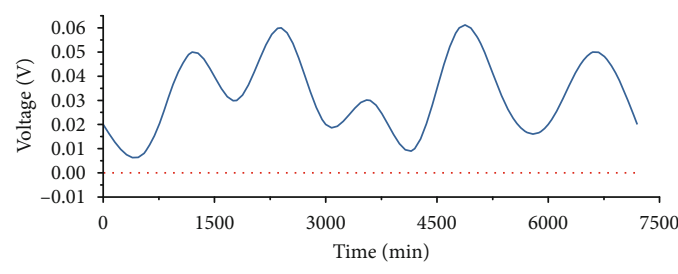

..... Nominal value _... Measure value

(a)

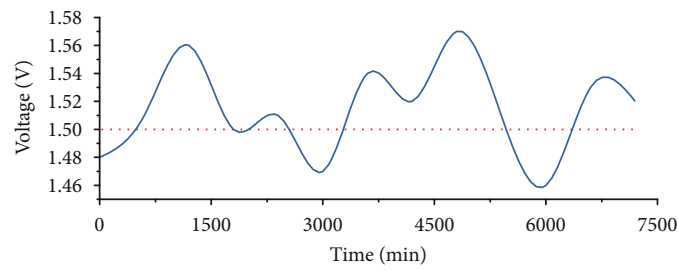

..... Nominal value

(c)

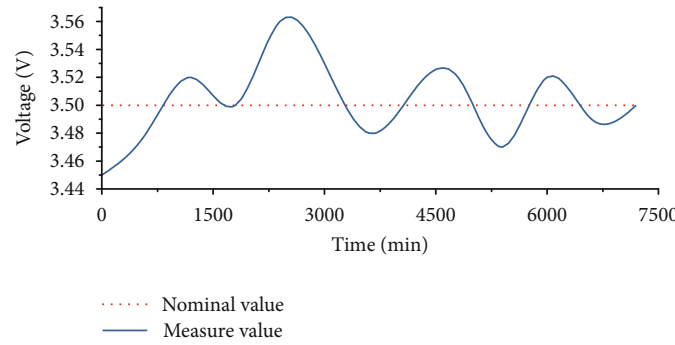

(e)

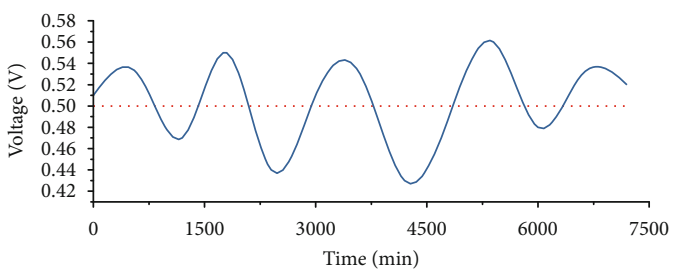

…. Nominal value
- Measure value

(b)

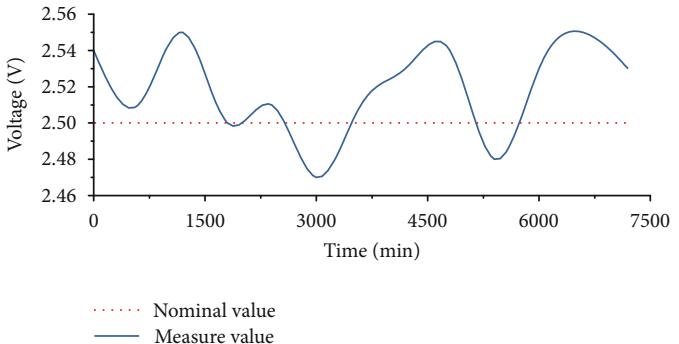

(d)

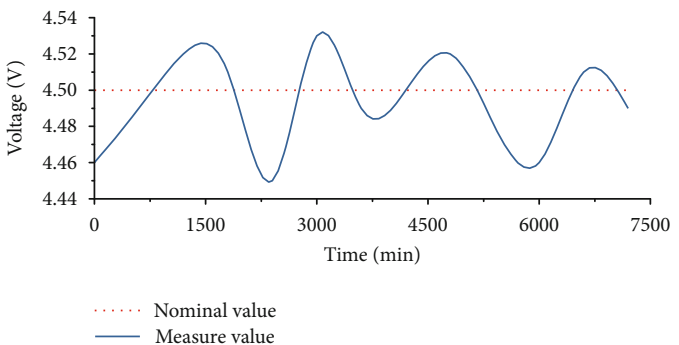

(f)

FIGURE 6: Voltage of measured point over time in the stability test with precipitation (a) $0 \mathrm{~mm}$, (b) $5 \mathrm{~mm}$, (c) $15 \mathrm{~mm}$, (d) $25 \mathrm{~mm}$, (e) $35 \mathrm{~mm}$, and (f) $45 \mathrm{~mm}$.

TABLE 2: The maximum voltage deviation and precipitation error of stability experiment.

\begin{tabular}{lccc}
\hline $\begin{array}{l}\text { Measuring } \\
\text { point [ml] }\end{array}$ & $\begin{array}{c}\text { Nominal } \\
\text { voltage [V] }\end{array}$ & $\begin{array}{c}\text { Maximum } \\
\text { deviation voltage } \\
{[\mathrm{V}]}\end{array}$ & $\begin{array}{c}\text { Maximum error of } \\
\text { precipitation [mm] }\end{array}$ \\
\hline 0 & 0 & 0.008 & 0.08 \\
50 & 0.5 & 0.567 & 0.67 \\
150 & 1.5 & 1.552 & 0.52 \\
250 & 2.5 & 2.541 & 0.41 \\
350 & 3.5 & 3.476 & -0.24 \\
450 & 4.5 & 4.543 & 0.43 \\
\hline
\end{tabular}

rain gauge are confined only to the date of test points showed in Table 1. In order to obtain the relationship between the measuring voltage and the precipitation for any point within the range, the least square method is used to fit the measured values in Table 1 to obtain the calibration curve, and the calibration curve is shown in Figure 5.

The expression of the calibration curve is

$$
u=0.0989 h+0.0394 \text {. }
$$

According to Figure 5 and Equation (7), the relationship between output voltage $u$ and precipitation $h$ is linear, which verifies the correctness of theoretical analysis of Equations (5) and (6) about circuit design. Equation (7) is the basis for setting the output voltage of the designed rain gauge.

In the stability experiment, the output voltage curves of each measuring point over time are shown in Figure 6. It can be seen from Figure 6 that the output voltage of each measured point fluctuates around the nominal value during the test process, and there is no gradual increase or decrease trend, indicating that the rain gauge measurement result is stable and reliable.

The maximum deviation voltage of each measuring point and the corresponding precipitation error during the stability trial are shown in Table 2. It can be seen from Table 2 that the maximum measurement error of precipitation is less than $1 \mathrm{~mm}$. When the precipitation is $50 \mathrm{~mm}$, the maximum error of the measured value is $0.67 \mathrm{~mm}$. The stability experiment results show that the rain gauge meets the requirements of stability and measurement accuracy.

In the process of environmental adaptability experiment, the output voltage of rain gauge has no change, which shows that the rain gauge has good adaptability and reliability under different temperature and humidity environments. After the 


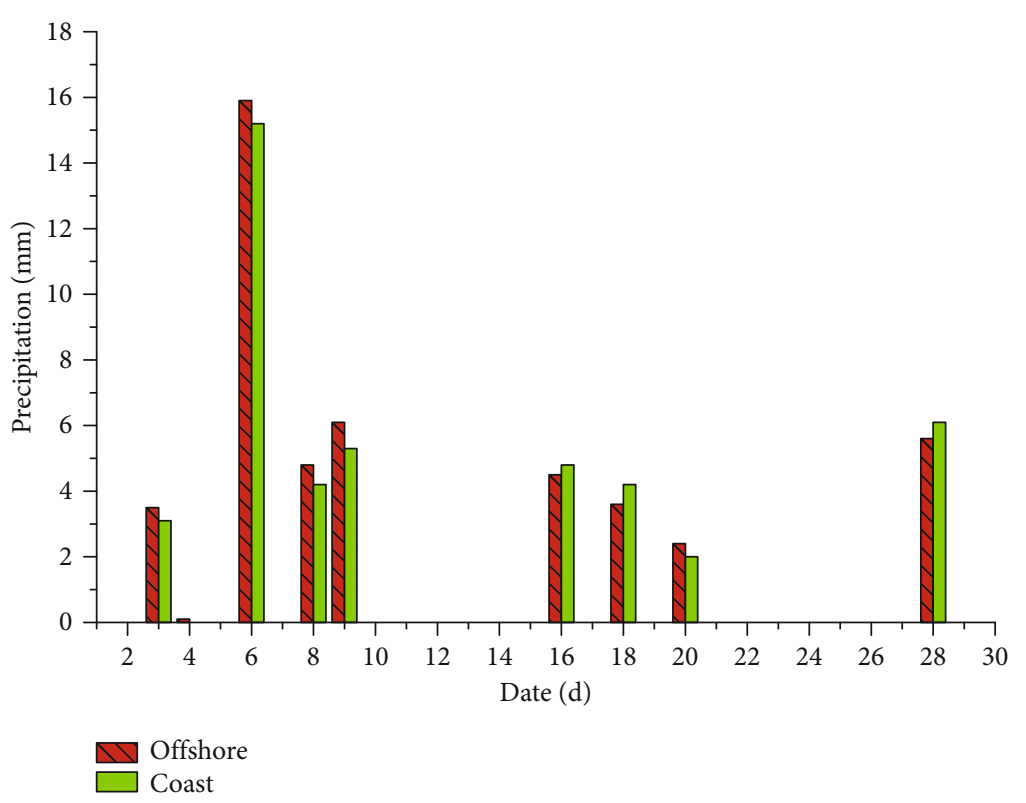

FIGURE 7: Precipitation comparison of offshore trial and coast observation.

salt spray experiment, there is no pitting corrosion and crack on the surface of rain gauge, which indicates that the rain gauge is able to resist salt spray corrosion.

The rain gauge was installed on the buoy platform for sea trial in May 2019. The daily measured offshore precipitation data from June $1^{\text {st }}, 2019$ to June 30, 2019, is shown in Figure 7. The coast precipitation in the same period is also given in Figure 7 to compare with the offshore precipitation to verify the measurement performance of the developed capacitive rain gauge in the marine environment. It can be seen from Figure 7 that the difference between the offshore precipitation and the coast precipitation offered by local meteorological observation is small, and the maximum difference is $0.8 \mathrm{~mm}$. The results show that the capacitive rain gauge can accurately measure the offshore precipitation.

\section{Conclusions}

A capacitive rain gauge is developed in this paper, which has been tested in laboratory and marine environment, and the performance of the rain gauge has met the design requirements. The following conclusions can be obtained: the hardware system in the mechanical structure and circuit board design of the rain gauge adopts anticorrosive material and technology, which exhibits good environmental adaptability in different temperature and humidity environments as well as salt fog environment. The relationship between the output voltage and precipitation is linear in theory and is proved by calibration and stability experiment. It also shows in the calibration test that the precipitation measurement accuracy of the rain gauge is less than $1 \mathrm{~mm}$, which achieves the design requirement. Based on the marine monitoring buoy, the capacitive rain gauge was tested in the marine environment. The rain gauge can measure the offshore precipitation with high accuracy and reliability comparing with the precipita- tion data observed on the coast. The developed capacitive rain gauge has obtained the calibration certificate and has valuable in onshore and offshore application.

\section{Data Availability}

The data used to support the findings of this study are available from the corresponding author upon request.

\section{Conflicts of Interest}

The authors declare no conflict of interest.

\section{Acknowledgments}

This research is supported by the National Natural Science Foundation of China (41976179), National Key Research and Development Project (2017YFC1403303), Natural Science Foundation of Shandong Province (ZR2019MF022), and Integration of Defence and Civilian Technologies Project of Shandong (2019JMRH0105).

\section{References}

[1] C. Kummerow, W. Barnes, T. Kozu, J. Shiue, and J. Simpson, "The tropical rainfall measuring mission (TRMM) sensor package," Journal of Atmospheric and Oceanic Technology, vol. 15, no. 3, pp. 809-817, 1998.

[2] K. Trenberth, L. Smith, T. Qian, A. Dai, and J. Fasullo, "Estimates of the global water budget and its annual cycle using observational and model data," Journal of Hydrometeorology, vol. 8, no. 4, pp. 758-769, 2007.

[3] S. Michaelides, V. Levizzani, E. Anagnostou, P. Bauer, T. Kasparis, and J. E. Lane, "Precipitation: Measurement, remote sensing, climatology and modeling," Atmospheric Research, vol. 94, no. 4, pp. 512-533, 2009. 
[4] A. Molini, L. G. Lanza, and P. La Barbera, "The impact of tipping-bucket raingauge measurement errors on design rainfall for urban-scale applications," Hydrological Processes, vol. 19, no. 5, pp. 1073-1088, 2005.

[5] C. Frei and C. Schär, "A precipitation climatology of the Alps from high-resolution rain-gauge observations," International Journal of Climatology, vol. 18, no. 8, pp. 873-900, 1998.

[6] L. L. Yang, Y. Yang, Y. C. Qi, X. X. Qiu, and Z. Q. Gong, “A case study of radar-derived quantitative precipitation estimation," Advanced Materials Research, vol. 726-731, pp. 45414546, 2013.

[7] C. Kummerow, Y. Hong, W. S. Olson et al., "The evolution of the Goddard profiling algorithm (GPROF) for rainfall estimation from passive microwave sensors," Journal of Applied Meteorology, vol. 40, no. 11, pp. 1801-1820, 2001.

[8] M. F. R. Gaona, A. Overeem, T. H. Raupach, H. Leijnse, and R. Uijlenhoet, "Rainfall retrieval with commercial microwave links in São Paulo, Brazil," Atmospheric Measurement Techniques, vol. 11, no. 7, pp. 4465-4476, 2018.

[9] Y. Xue, X. C. Liu, T. C. Gao, C. Y. Yang, K. Song, and H. K. Gao, "Regional attenuation correction of weather radar using a distributed microwave-links network," Advances in Meteorology, vol. 2017, 8 pages, 2017.

[10] Y. X. Qin, Z. Q. Chen, Y. Shen, S. P. Zhang, and R. H. Shi, "Evaluation of satellite rainfall estimates over the Chinese mainland," Remote Sensing, vol. 6, no. 11, pp. 11649-11672, 2014.

[11] K. U. V. Murali, S. K. Das, S. M. Deshpande, S. L. Doiphode, and G. Pandithurai, "The assessment of global precipitation measurement estimates over the Indian subcontinent," Earth and Space Science, vol. 4, no. 8, pp. 540-553, 2017.

[12] S. Prakash and R. M. Gairola, "Validation of TRMM-3B42 precipitation product over the tropical Indian Ocean using rain gauge data from the RAMA buoy array," Theoretical and Applied Climatology, vol. 115, no. 3-4, pp. 451-460, 2014.

[13] R. Xu, F. Q. Tian, L. Yang, H. C. Hu, H. Lu, and A. Z. Hou, "Ground validation of GPM IMERG and TRMM 3B42V7 rainfall products over southern Tibetan plateau based on a high-density rain gauge network," Journal of Geophysical Research: Atmospheres, vol. 122, no. 2, pp. 910-924, 2017.

[14] A. Baronetti, F. Acquaotta, and S. Fratianni, "Rainfall variability from a dense rain gauge network in north-western Italy," Climate Research, vol. 75, no. 3, pp. 201-213, 2018.

[15] M. D. Pollock, G. O'Donnell, P. Quinn et al., "Quantifying and mitigating wind-induced undercatch in rainfall measurements," Water Resources Research, vol. 54, no. 6, pp. 38633875, 2018.

[16] M. Löffler-Mang and J. Joss, "An optical disdrometer for measuring size and velocity of hydrometeors," Journal of Atmospheric and Oceanic Technology, vol. 17, no. 2, pp. 130-139, 2000.

[17] E. M. Trono, M. L. Guico, N. J. C. Libatique, G. L. Tangonan, and A. P. F. Parrenas, "Rainfall monitoring using acoustic sensors," in TENCON 2012 IEEE Region 10 Conference, pp. 1-6, Cebu, 2012

[18] J. Förster, G. Gust, and S. Stolte, “A piezoelectrical rain gauge for application on buoys," Journal of Atmospheric and Oceanic Technology, vol. 21, no. 2, pp. 179-193, 2010.

[19] G. D. Quartly, T. H. Guymer, and K. G. Birch, "Back to basics: measuring rainfall at sea: part 1 - In situ sensors," Weather, vol. 57, no. 9, pp. 315-320, 2002.
[20] A. W. Jayawardena and R. B. Rezaur, "Measuring drop size distribution and kinetic energy of rainfall using a force transducer," Hydrological Processes, vol. 14, no. 1, pp. 37-49, 2000.

[21] G. J. Ciach, "Local random errors in tipping-bucket rain gauge measurements," Journal of Atmospheric and Oceanic Technology, vol. 20, no. 5, pp. 752-759, 2003.

[22] H. Y. Li, Q. Li, X. Li, and J. L. Song, "Discussion on the algorithms of a new siphon rain gauge," WSEAS Transactions on Circuits and Systems, vol. 9, no. 6, pp. 389-398, 2010.

[23] M. Colli, L. G. Lanza, and P. La Barbera, "Performance of a weighing rain gauge under laboratory simulated time-varying reference rainfall rates," Atmospheric Research, vol. 131, pp. 3-12, 2013.

[24] S. Iida, D. F. Levia, K. Nanko et al., "Correction of canopy interception loss measurements in temperate forests: a comparison of necessary adjustments among three different rain gauges based on a dynamic calibration procedure," Journal of Hydrometeorology, vol. 19, no. 3, pp. 547-553, 2018.

[25] V. Kvicera and M. Grabner, "Dynamic calibration of tippingbucket raingauges and rainfall intensity data processing," in 2006 First European Conference on Antennas and Propagation, pp. 1-5, Nice, France, 2006.

[26] X. Zhang, H. Y. Zhao, H. Y. Liang, and Y. J. Wang, "Analysis of precipitation measuring accuracy between weighing type and siphon type rain gauge," China Flood \& Drought Management, vol. 30 , no. 3, pp. 32-36, 2020.

[27] S. E. Yuter and W. S. Parker, "Rainfall measurement on ship revisited: the 1997 PACS TEPPS cruise," Journal of Applied Meteorology, vol. 40, no. 6, pp. 1003-1018, 2001.

[28] K. P. Bowman, "Comparison of TRMM precipitation retrievals with rain gauge data from ocean buoys," Journal of Climate, vol. 18, no. 1, pp. 178-190, 2005.

[29] Q. Y. Wu and Y. L. Wang, "Comparison of oceanic multisatellite precipitation data from tropical rainfall measurement Mission and global precipitation measurement mission datasets with rain gauge data from ocean buoys," Journal of Atmospheric and Oceanic Technology, vol. 36, no. 5, pp. 903-920, 2019.

[30] P. Azimi and H. Golnabi, "Precise formulation of electrical capacitance for a cylindrical capacitive sensor," Journal of Applied Sciences, vol. 9, no. 8, pp. 1556-1561, 2009. 